\title{
Distribusi Spasial Karbon Monoksida Ambien di Lingkungan Kampus Universitas Gadjah Mada Yogyakarta
}

\author{
Dian Hudawan Santoso \\ Jurusan Teknik Lingkungan, Fakultas Teknologi Mineral, \\ Universitas Pembangunan "Veteran" Nasional, Yogyakarta.
}

\begin{abstract}
Abstrak
Penelitian ini bertujuan untuk mengetahui bagaimana distribusi spasial CO, menganalisis pengaruh kepadatan kendaraan bermotor, kondisi meteorologi dan penggunaan lahan terhadap konsentrasi CO di Kampus UGM. Digunakan metode moving observation technique untuk mendapatkan data primer. Hasil pengukuran yaitu: bagian utara CO pagi 20,1 ppm; siang 17,4 ppm dan sore 24,3 ppm; bagian tengah CO pagi 15,3 ppm, siang 14,7 ppm dan sore 13,1 ppm; bagian selatan CO pagi 18,4 ppm siang 18,5 ppm dan sore 28,3 ppm. Persamaan hasil regresi linier berganda yang paling sesuai dengan tidak memasukkan variabel iklim mikro adalah $C O=11,744+0,002 K \_B$. Ajusted $R$ Square sebesar 0,276 selalu lebih kecil dari $R$ square. Konsentrasi CO ambien di kampus UGM di bawah ambang batas baku mutu DIY yaitu 35 ppm.
\end{abstract}

Kata Kunci : CO, polusi udara, kepadatan kendaraan bermotor

\section{PENDAHULUAN}

Kesadaran oleh lingkungan hidup dipicu oleh perasaan terancam, khususnya yang berasal dari sektor industri, transportasi, dan pertanian. Kesadaran ini diawali oleh negara-negara maju yang memiliki banyak sektor industri, melibatkan banyak kendaraan bermotor untuk mendukung berbagai mobilitas masyarakatya dan pertanian, modern yang menggunakan pestisida (Soemarwoto, 2001). Sektor transportasi merupakan sektor yang melayani masyarakat terutama dalam hal pengangkutan dan hubungan antar wilayah.

Jalan Kaliurang yang secara fisik membelah kampus UGM menjadi bagian barat dan bagian timur sebenarnya merupakan permasalahan tersendiri bagi keberlangsungan berbagai macam kegiatan kampus. Disadari ataupun tidak dengan terbelahnya kampus UGM menjadi dua blok yaitu barat dan timur oleh keberadaan Jalan Kaliurang menyebabkan kurangnya estetika kampus, kebisingan dan tentunya pencemaran udara. Akibat adanya dampak tersebut muncul isu-isu akan ada penutupan Jalan Kaliurang yang membelah kampus UGM dan dialihkan ke barat atau timur. Namun ketika Jalan Kaliurang itu ditutup maka berbagai permasalahan yang lain juga akan timbul mengingat masih betapa pentingnya fungsi Jalan Kaliurang dalam kondisi saat ini dan dampak sosialnya bisa jadi akan lebih tinggi. 
Adanya jalan raya sepanjang 1.150 meter di lingkungan kampus UGM merupakan fenomena aktual yang cukup menarik untuk diteliti dalam keterkaitannya dengan masalah kualitas udara ambien khususnya kandungan $\mathrm{CO}$ atau kadar karbon monoksida. Monitoring atau pemantauan tentang kualitas udara di lingkungan kampus masih sangat jarang dilakukan oleh pemerintah atau berbagai instansi di Yogyakarta.

Berdasarkan pada latar belakang yang telah dikemukakan, dapat dirumuskan permasalahan sebagai berikut:

1. Seberapa besar konsentrasi karbon monoksida (CO) ambien dan bagaimana distribusinya secara spasial di lingkungan kampus UGM ?

2. Bagaimana pengaruh faktor kepadatan kendaraan bermotor serta faktor-faktor iklim mikro (suhu, kecepatan angin, kelembaban) dan penggunaan lahan terhadap kadar CO di lingkungan kampus UGM?

\section{Metodologi Penelitian}

Data yang digunakan dalam penelitian ini berupa data primer dan data sekunder. Data primer diantaranya berupa jumlah kepadatan kendaraan bermotor di UGM yang melewati Jalan Kaliurang, kadar CO, temperatur, kelembaban, kecepatan angin. Data sekunder berupa peta Administrasi Kabupaten Sleman, peta Administrasi Kecamatan Depok, denah kampus UGM dan baku mutu udara ambien udara propinsi DIY No. 153 tahun 2002.

Tabel 1. Alat-alat dalam penelitian

\begin{tabular}{|c|l|l|}
\hline No & \multicolumn{1}{|c|}{ Alat } & \multicolumn{1}{c|}{ Fungsi } \\
\hline 1. & Software ArcView 3.3 & Pembuatan peta digital \\
\hline 2. & Program SPSS & Analisis statistik \\
\hline 3. & CO analyzer/karbon monoksor & Mengukur kadar CO \\
\hline 4. & Weather meter & $\begin{array}{l}\text { Mengukur suhu, kelembaban dan } \\
\text { kecepatan angin. }\end{array}$ \\
\hline 5. & Kamera digital & Perekam visual kenampakan di lapangan \\
\hline 6. & Hand counter/manual & Menghitung jumlah kendaran bermotor \\
\hline 7. & Stop watch atau jam & Penghitung waktu \\
\hline 8. & Checklist & Mencatat data lapangan \\
\hline
\end{tabular}


Data primer dikumpulkan dengan mengadakan survei dan pengukuran langsung di lapangan. Observasi lapangan, yaitu metode untuk memperoleh data lapangan dengan cara pengamatan, pengukuran dan pencatatan terhadap fenomena yang diteliti (Matra, 1998).

Penentuan titik-titik pengamatan menggunakan teknik purposive sampling, yaitu pengambilan sampel berdasarkan maksud dan tujuan tertentu (Sugiyono, 2009). Pengumpulan data primer yang diambil dari titik-titik pengamatan, menggunakan moving observation technique, yaitu suatu teknik pengambilan data dalam satuan waktu tertentu dengan beberapa titik pengamatan yang berbeda. Dengan teknik tersebut diharapkan dapat menghasilkan data yang tepat dari beberapa titik pengamatan dalam range waktu yang hampir sama. Pengukuran data primer menggunakan alat-alat seperti CO analyzer/karbon monoksor, weathermeter, stopwatch atau jam, dan checklist. Data sekunder diperoleh dari literatur, interpretasi peta, dan dari instansi yang terkait.

Waktu pengukuran dalam penelitian ini dibagi menjadi tiga waktu yaitu pagi, siang dan sore untuk tiap harinya yaitu rentang waktu pagi pukul 06.00-08.00, rentang waktu siang pukul 12.00-14.00, dan rentang waktu sore pukul 16.00-18.00. Pembagian waktu menjadi tiga bagian tersebut dikarenakan tiap waktu baik pagi, siang atau sore memiliki perbedaan dalam aktivitas masyarakat atau pada saat-saat tertentu masyarakat memiliki jam-jam sibuk tak terkecuali dengan aktivitas kampus, selain itu keadaan suhu, kelembaban dan ada kecepatan angin yang berbeda antara pagi, siang dan sore, sehingga dengan pembagian waktu tersebut diasumsikan dapat menunjukkan hasil kadar CO yang tidak sama tiap waktunya. Pertimbangan yang lainnya adalah tidak menyertakan waktu petang atau malam seperti pukul 18.00 ke atas karena jam efektif belajar mengajar di kampus UGM tidak sampai malam atau sebelum jam 18.00 walaupun kondisi Jalan Kaliurang saat-saat tersebut juga dimungkinkan masih dipadati oleh kendaraan bermotor yang dapat mengemisikan $\mathrm{CO}$ lebih banyak lagi.

Pada setiap titik utama dilakukan pengukuran atau penghitungan kendaraan bermotor selama 1 jam sesuai dengan Baku Mutu Udara Ambien Propinsi DIY No. 153 tahun 2002 yaitu pada masingmasing waktu pagi, siang dan sore selama 7 hari.

Titik-titik sampel yang lain cukup dihitung kondisi meteorologisnya seperti suhu, kelembaban, kecepatan dan arah angin bersamaan dengan penghitugan kendaraan bermotor dan $\mathrm{CO}$ di titik utama. 

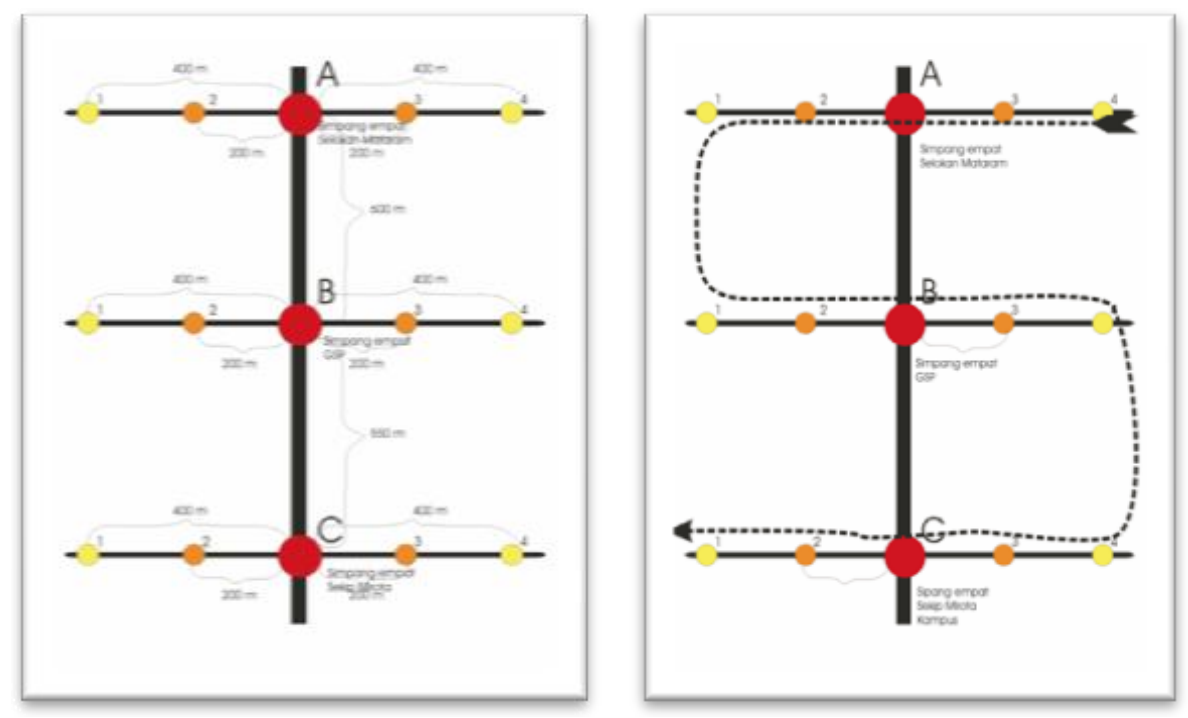

Gambar 1. Titik Pengukuran dan Skema Teknik Pengambilan Data Lapangan secara Moving Observation

\section{Metode Analisis Data}

1. Analisis Deskriptif

Analisis deskriptif digunakan untuk menjelaskan bagaimana pencemaran udara ambien khususnya konsentrasi CO ambien yang terjadi setelah dilakukan penelitian berdasarkan jumlah kendaraan bermotor, dengan keterkaitannya antara kandungan CO, suhu, kelembaban, kecepatan angin dan penggunaan lahan. Analisis deskriptif menggunakan grafik dan gambar untuk mempermudah dalam pembahasannya.

\section{Analisis Grafis}

Analisis grafis ini berupa peta dan grafik. Peta dalam analisis ini akan menampilkan perbandingan-perbandingan antara data yang satu dengan data yang lain, dalam hal ini adalah mengenai persebaran $\mathrm{CO}$ yang dipengaruhi oleh jumlah kepadatan kendaraan bermotor, suhu, kelembaban, kecepatan angin dan land use di daerah penelitian.

3. Analisis Statistik

Analisis statistik digunakan untuk membuktikan hipotesis secara pasti. Analisis yang digunakan adalah uji normalitas, korelasi, regresi dan uji hipotesis dengan taraf signifikansi/level of significant $\gamma=0,01$ / derajat kepercayaan $95 \%$. 
a. Uji Normalitas

Kondisi ini berfungsi untuk mengetahui apakah ada hubungan antara variabel-variabel yang diuji dan menyatakan keeratan hubungan. Data yang diperoleh berupa skala data rasio sehingga termasuk data statistik parameter. Oleh karena itu, korelasi yang digunakan adalah Reason Product Moment dengan rumus (Walpole, 1995).

$$
\begin{aligned}
& r_{x y}=\frac{\sum\left(x_{1}-\bar{x}\right)(y-\bar{y})}{\sqrt{\left(\sum\left(x_{1}-\bar{x}\right)^{2}\right)\left(\sum\left(y_{1}-y\right)^{2}\right)}} \\
& r_{x y}=\text { besarnya korelasi antara variabel } x \text { dengan variabel } y \\
& x_{1}=\text { variabel } x \\
& \bar{x}=\text { rata-rata } x \\
& y_{1}=\text { variabel } y \\
& \bar{y}=\text { rata-rata } y
\end{aligned}
$$

Secara sederhana, nilai $\mathrm{r}$ yang lebih besar dari 0,5 mempunyai korelasi yang kuat sedangkan nilai r yang kurang dari 0,5 berarti mempunyai korelasi yang lemah (Santoso, 2004). Selain itu, korelasi juga dinyatakan dengan tanda (+) dan negatif (-). Korelasi bertanda positif berarti korelasi tersebut memiliki hubungan yang searah dengan korelasi bertanda negatif menandakan hubungan yang tidak searah atau berkebalikan.

Analisis korelasi ini menggunakan bantuan program SPSS.

b. Regresi Linier berganda

Regresi ini menggunakan variabel bebas. Variabel terikat pada regresi berganda ini adalah CO. Variabel bebasnya adalah kendaraan bermotor dalam satuan smp, suhu udara kelembaban dan kecepatan angin.

Regresi digunakan untuk menyatakan antara variabel-variabel yang diuji. Regresi mengacu pada tujuan prediksi atau peramalan bagaimana sebuah variabel bebas (Santoso, 2004).

$\mathrm{Y}=\mathrm{a} 1 \mathrm{x} 1+\mathrm{a} 2 \times 2+\mathrm{a} 3 \times 3+\mathrm{a} 4 \times 4+\mathrm{k}$

$\mathrm{A}=$ koefisien variabel bebas

$\mathrm{K}=$ konstanta 
$\mathrm{X}$ = variabel bebas (K_B, suhu, kelembaban, kec_angin))

$\mathrm{Y}=$ variabel bebas terikat $(\mathrm{CO})$

$\mathrm{n}=$ jumlah variabel bebas

Analisis regresi dilakukan menggunakan Program SPSS. Metode regresi yang digunakan adalah metode Enter. Metode ini secara otomatis akan menghasilkan korelasi sehingga lebih praktis daripada metode yang lainnya.

c. Uji Hipotesis

Uji hipotesis digunakan untuk menguji apakah koefisien korelasi regresi signifikan atau tidak. Menggunakan uji hipotesis asosiatif. Uji dilakukan dua sisi karena akan dicari ada tidaknya hubungan bukan lebih besar atau lebih kecil. Uji hipotesis untuk menguji koefisien korelasi adalah (Santoso, 2004):

\section{Hasil dan Pembahasan}

Pada titik pengukuran (A Utama) di Jalan Kaliurang Selokan Mataram memiliki variasi kadar CO pagi sebesar 20,1 ppm, siang hari sebesar 17,4 ppm dan sore hari kadar CO sebesar 24,3 ppm.

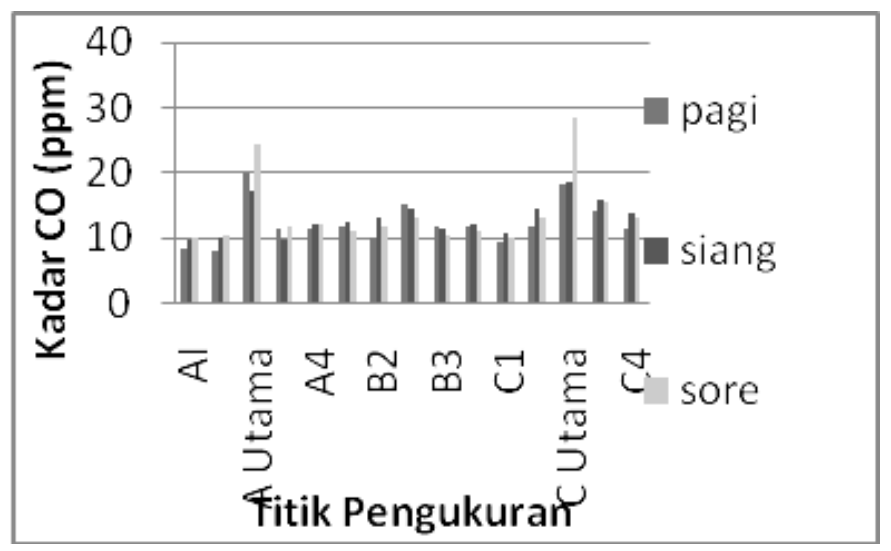

Gambar 2. Distribusi Spasial Konsentrasi CO Ambien di Lingkungan Kampus UGM (hasil rata-rata selama seminggu)

Pada titik pengukuran (B Utama) di Jalan Kaliurang simpang empat Graha Sabha Pramana konsentrasi CO memiliki variasi yang hampir sama dengan titik-titik pengukuran di sebelah barat maupun sebelah timur Jalan Kaliurang. Pada pengukuran pagi hari besar konsentrasi CO adalah 15,3 ppm, pada waktu siang hari sebesar 14,7 ppm dan sore hari sebesar 13,1 ppm. 
Pada titik pengukuran (C Utama) di Jalan Kaliurang simpang empat Mirota Kampus kandungan CO ambien agak sedikit ekstrim jika dibandingkan dengan kadar $\mathrm{CO}$ di 2 titik utama yang lainnya dimana pada pagi hari kandungan CO nya sebesar 18,4 ppm, pada siang hari 18,5 dan pada sore hari sebesar 28,3 ppm.

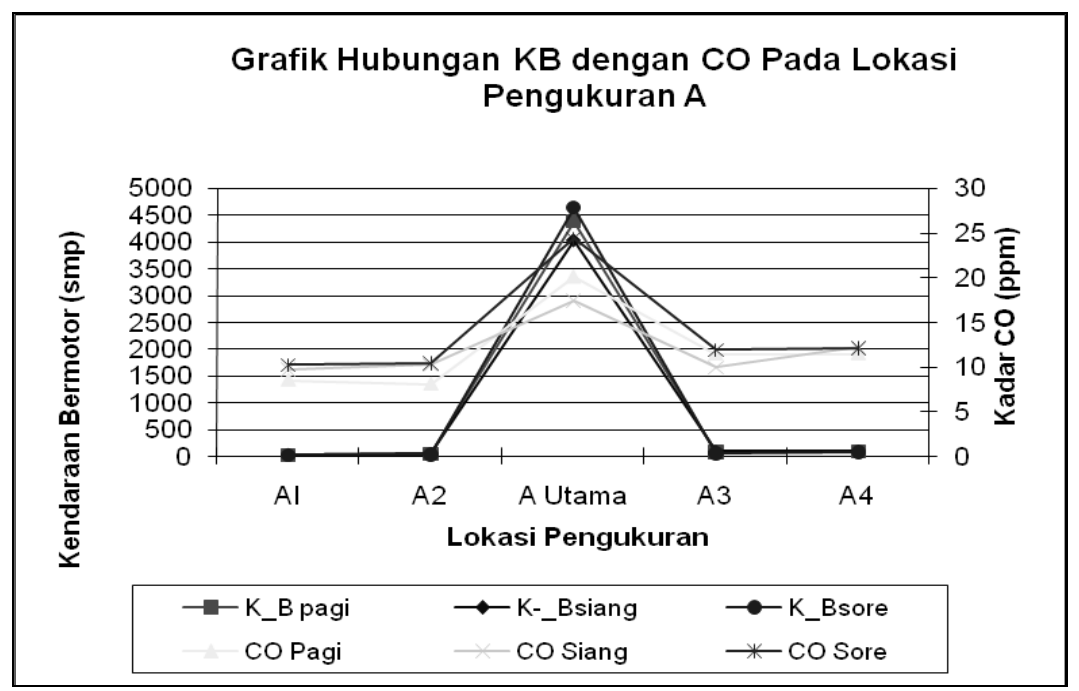

Gambar 3. Hubungan CO dengan Kepadatan Kendaraan Bermotor pada Lokasi A.

Hubungan antara $\mathrm{CO}$ dengan kepadatan kendaraan bermotor yang dinyatakan dalam smp pada lokasi pengukuran A. Secara umum hubungan ini bernilai positif dan kuat artinya jika kepadatan kendaraan bermotor besar maka kandar CO juga semakin besar.

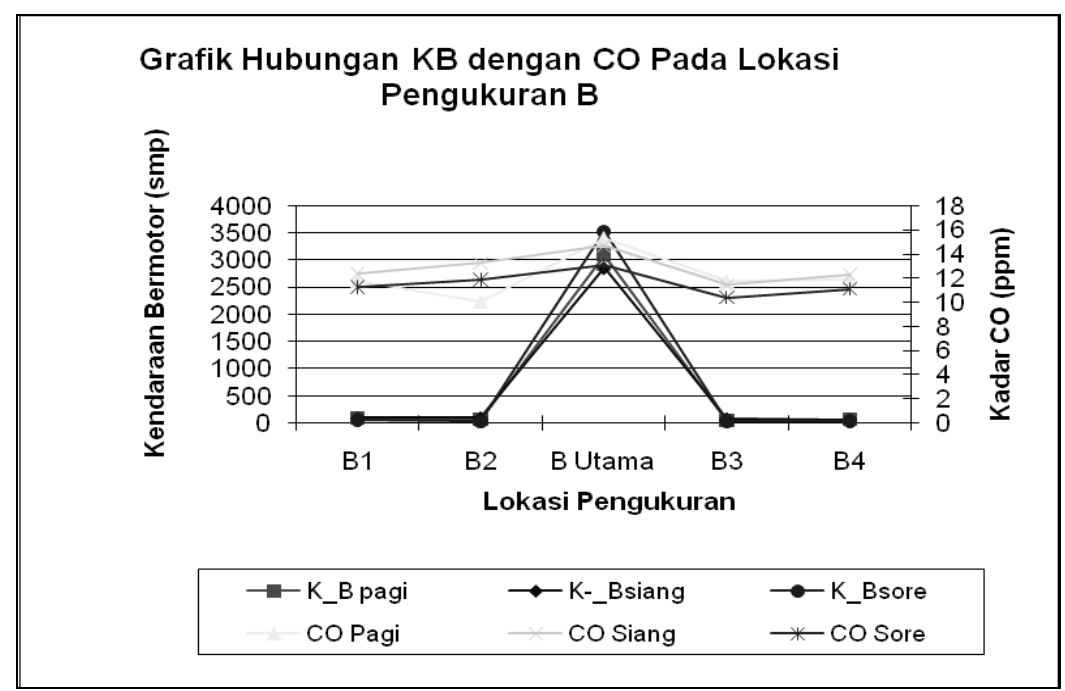

Gambar 4. Hubungan CO dengan Kepadatan Kendaraan Bermotor pada Lokasi B

Hubungan antara CO dengan kepadatan kendaraan bermotor yang dinyatakan dalam smp pada lokasi pengukuran B. Secara umum hubungan ini bernilai positif dan kuat artinya jika kepadatan kendaraan bermotor besar maka kandar CO juga semakin besar. 


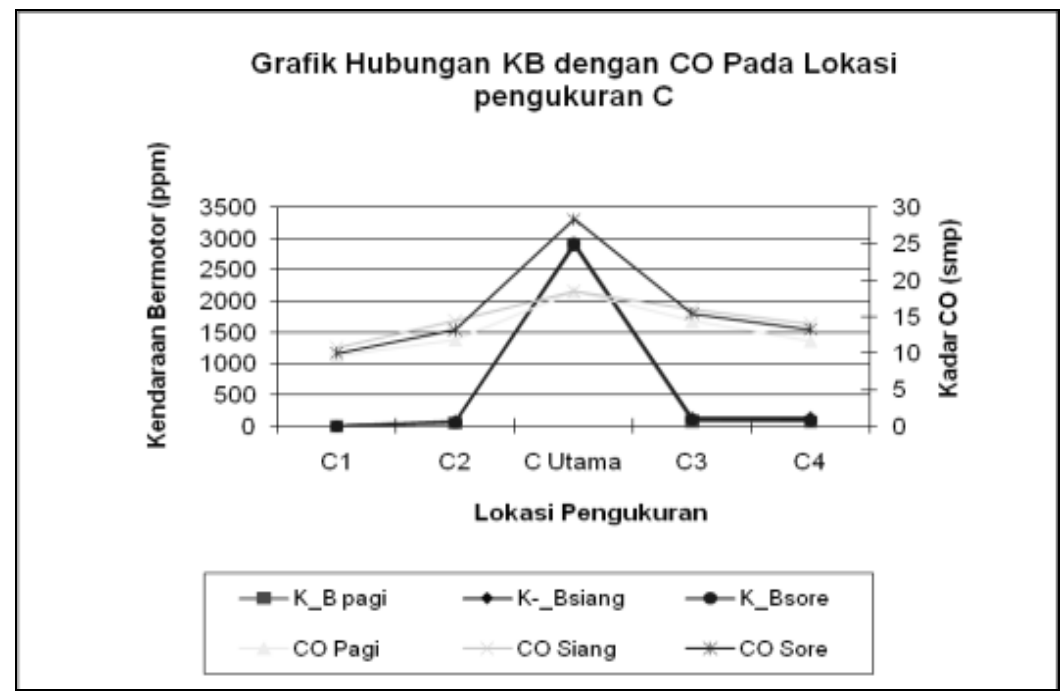

Gambar 5. Hubungan CO dengan Kepadatan Kendaraan Bermotor Pada Lokasi C

Hubungan antara CO dengan kepadatan kendaraan bermotor yang dinyatakan dalam smp pada lokasi pengukuran C. Secara umum hubungan ini bernilai positif dan kuat artinya jika kepadatan kendaraan bermotor besar maka kandar CO juga semakin besar.

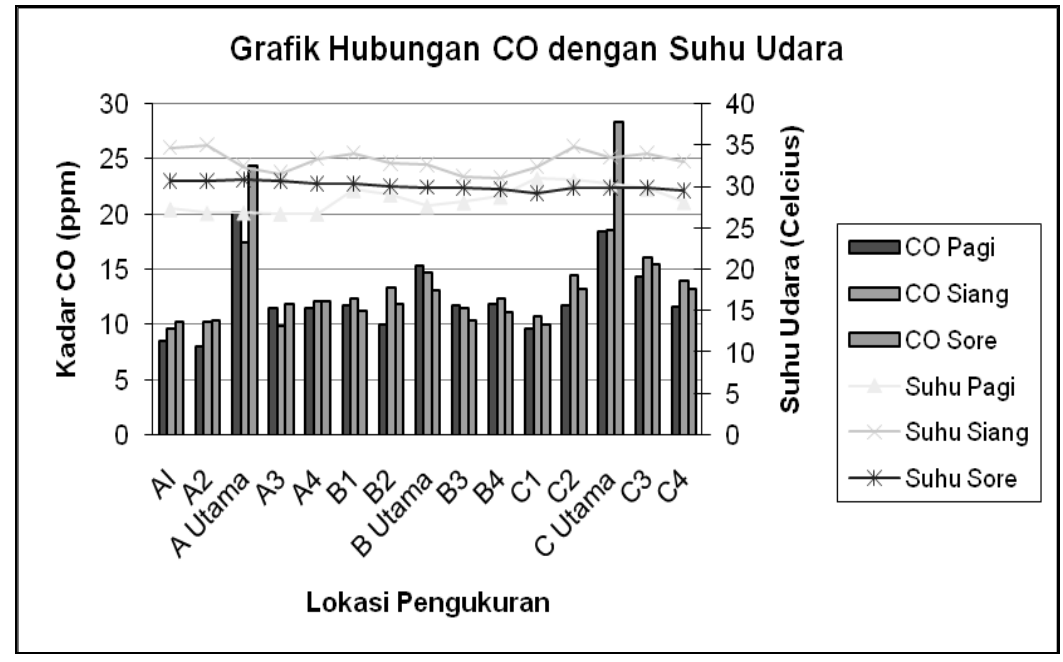

Gambar 6. Hubungan CO dengan Suhu Udara

Telah terjadi perubahan konsentrasi $\mathrm{CO}$ yang cukup ekstrim terutama pada titik-titik pengukuran utama tetapi tidak diikuti oleh perubahan secara ekstrim oleh suhu udara. Jadi dalam kasus ini pengaruh suhu udara dalam menentukan nilai konsentrasi $\mathrm{CO}$ ambien tidak begitu besar. 


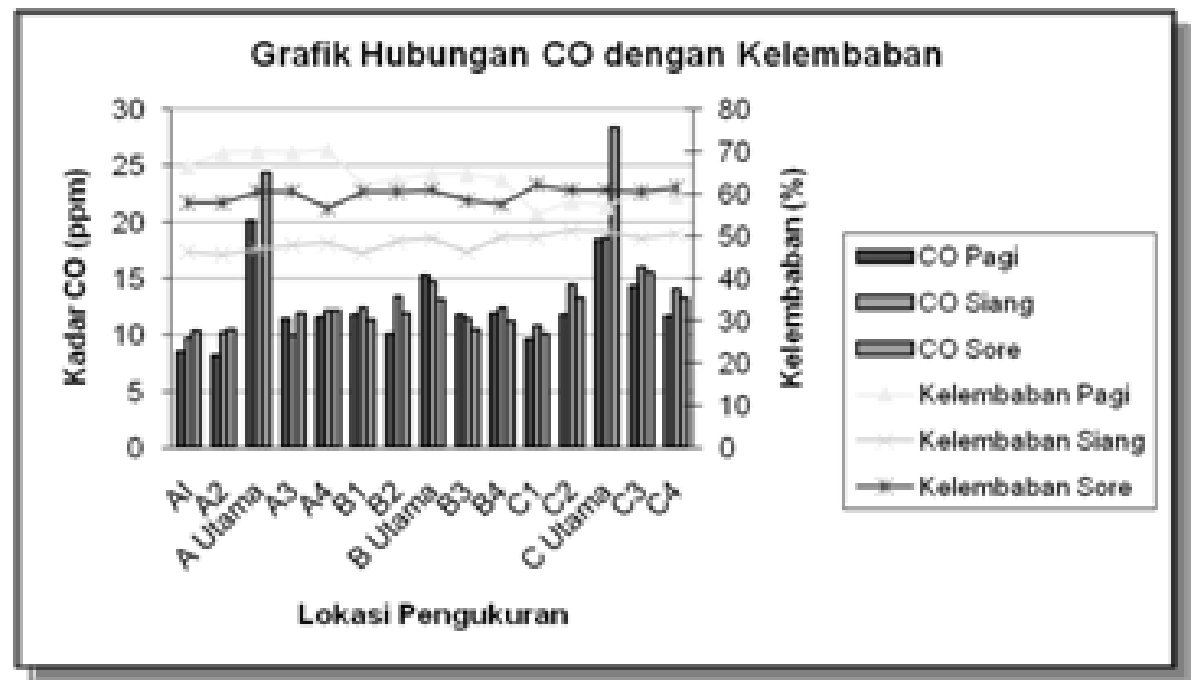

Gambar 7. Distribusi Rata-rata Kelembaban Udara di Lingkungan Kampus UGM

Nilai kelembaban udara yang tertinggi adalah 70,3\% yang terjadi di titik pengukuran A4 dekat dengan lembah UGM. Pada siang hari rata-rata kelembaban udaranya relatif kecil dengan kelembaban udara yang tertinggi pada siang hari adalah $51,1 \%$ yang terjadi di lokasi pengukuran $\mathrm{C}$ Utama dekat dengan Mirota Kampus. Pada sore hari kelembaban yang tertinggi terjadi pada titik C1 di permukiman penduduk Blimbingsari yaitu sebesar $62,2 \%$.

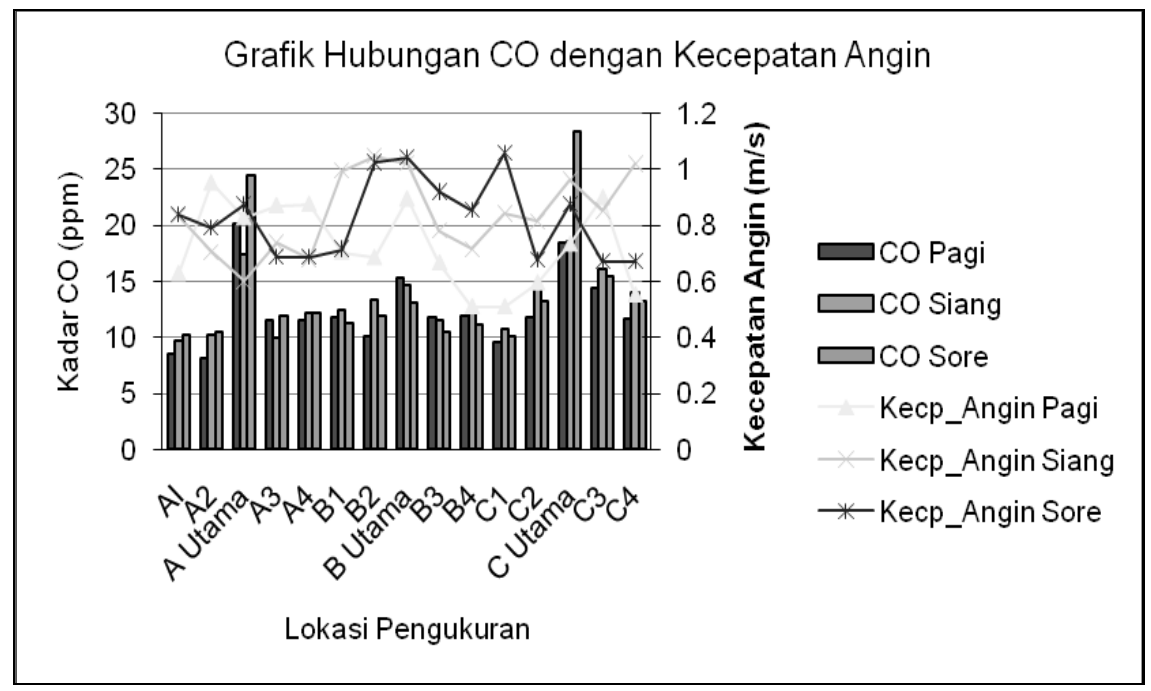

Gambar 8. Hubungan CO dengan Kecepatan Angin di Lingkungan Kampus UGM

Kecepatan angin dan konsentrasi CO tidak memunculkan suatu pola yang tegas baik pola searah atau saling mengkuti maupun pola berlawanan. Pola variasi pada konsentrasi CO cenderung lebih tegas, sedangkan pada kecepatan angin tidak begitu tegas sehingga ketidakjelasan pola tersebut dapat memunculkan anggapan bahwa dalam skala mikro pengaruh kecepatan angin terhadap konsentrasi $\mathrm{CO}$ tidak begitu besar. 


\section{Kesimpulan}

1. Terkait dengan konsentrasi $\mathrm{CO}$ ambien dan distribusinya secara spasial di lingkungan kampus UGM adalah:

a. Distribusi spasial konsentrasi karbon monoksida ambien di lingkungan kampus UGM secara umum dapat dibagi menjadi tiga bagian yaitu pada titik pengukuran di simpang empat Selokan Mataram mewakili bagian utara kampus UGM dengan rata-rata konsentrasi CO antara 17 - 24 ppm, pada titik pengukuran di simpang empat dekat Graha Sabha Pramana mewakili bagian tengah kampus UGM dengan rata-rata konsentrasi CO antara 13-15 ppm, dan pada titik pengukuran di simpang empat Mirota Kampus mewakili bagian selatan kampus UGM dengan rata-rata konsentrasi CO antara 18-18 ppm.

b. Konsentrasi karbon monoksida di sebelah barat Jalan Kaliurang memiliki rata-rata lebih rendah dari pada konsentrasi CO di sebelah timur Jalan Kaliurang yaitu 11 ppm berbanding 12,35 ppm.

c. Konsentrasi CO secara umum di kampus UGM pada hari kerja lebih tinggi dari pada saat hari libur karena aktivitas masyarakat lebih banyak dilakukan pada hari kerja dari pada pada hari libur.

d. Konsentrasi karbon monoksida (CO) ambien di lingkungan kampus UGM tidak melebihi ambang batas baku mutu PP. No.153 Prop. DIY Tahun 2002 yaitu 35 ppm sehingga masih nyaman secara kesehatan bagi civitas akademik kampus UGM dan masyarakat.

2. Terkait dengan kepadatan kendaran bermotor, iklim mikro dan penggunaan lahan terhadap konsentrasi CO ambien adalah :

a. Kendaraan bermotor memiliki korelasi yang paling kuat $(0,526)$ terhadap CO sehingga sangat berpengaruh terhadap besar kecilnya konsentrasi CO ambien di lingkungan kampus UGM.

b. Variabel iklim mikro yang berupa suhu, kelembaban, dan kecepatan angin, memiliki korelasi dan derajat signifikansi yang lemah terhadap konsentrasi CO sehingga pengaruhnya terhadap CO ambien di lingkungan kampus UGM sangat kecil.

c. Variabel iklim mikro diabaikan dalam regresi linier berganda karena memiliki korelasi yang sangat lemah sehingga persamaan hasil regresi linier berganda yang paling sesuai dengan tidak memasukkan variabel iklim mikro adalah $\mathrm{CO}=11,744+0,002$ K_B dengan KD sebesar $27,6 \%$. 


\section{Saran}

1. Skala penelitian ini merupakan skala lokal atau skala mikro sehingga hasilnya tidak dapat digeneralisir terhadap wilayah lain yang lebih luas, oleh karena itu perlu adanya penelitian lain yang lebih kompleks dengan parameter yang lebih rinci untuk mengetahui permasalahan $\mathrm{CO}$ ambien secara lebih menyeluruh.

2. Konsentrasi CO ambien yang masih dibawah baku mutu di sekitar UGM saat ini tidak menutup kemungkian suatu saat akan semakin tinggi dan menggangu kesehatan masyarakat karena tren peningkatan jumlah penduduk, penggunaan lahan dan kendaraan bermotor semakin tinggi sehingga perlu ditingkatkan pengelolaan lingkungan maupun manajemen transportasi di lingkungan kampus.

3. Pengukuran di lapangan dalam proses pengambilan data primer merupakan bagian yang cukup penting dalam sebuah penelitian sehingga membutuhkan perencanaan waktu yang matang, terutama pada penelitian tentang CO harus memperhatikan cuaca atau curah hujan agar tidak kehilangan data akibat terjadi hujan.

4. Untuk mendapatkan hasil yang lebih baik dan akurat perlu dilakukan sistem pemantauan kualitas udara secara terprogram dan berkesinambungan, tidak hanya di lingkungan kampus UGM saja tetapi di lingkungan kampus yang lain ataupun tempat-tempat strategis lainnya.

5. Wacana akan ditutupnya Jalan Kaliurang memang sebaiknya menjadi pertimbangan yang matang oleh pengelola kampus UGM. Walaupun pencemaran udara (khususnya CO) belum begitu berbahaya namun permasalahan lain akibat adanya Jalan Kaliurang perlu dipikirkan lagi sehingga ada dan tidak adanya Jalan Kaliurang di lingkungan kampus UGM tetap akan memberikan keamanan dan kenyamanan bagi masyarakat kampus dan sekitarnya.

\section{DAFTAR PUSTAKA}

Crosby, Donald G., 1998, Environmental Toxicology And Chemistry, $6^{\text {th }}$ Ed, New York, Oxford Iniversity Press

Dix, H.M., 1981, Environmental Pollution, John Wiley and Sons, New York

Mukono, H.J., 1997, Pencemaran Udara dan Pengaruhnya Terhadap Gangguan Pernafasan, Airlangga University, Surabaya

Muslim, Burhan, 1997, Kadar Karbon Monoksida (CO) di dalam dan di Luar Bangunan Toko di Kotamadya Yogyakarta, Tesis, Program Pasca Sarjana Fakultas Geografi UGM, Yogyakarta 
Neighburger, Edinger, Bonner, 1995, Memahami Lingkungan Atmosfer Kita, Penerbit ITB, Bandung.

Santoso, S., 2000, Buku Latihan SPSS Statistik Parametrik, PT Elek Media Gramedia, Jakarta

Soemarwoto, O., 2001, Ekologi, Lingkungan dan Pembangunan, Jakarta: Djambatan

Sugiyono, 2009, Statistik untuk Penelitian, Bandung: Alfabeta.

Surat Keputusan Gubernur DIY Nomor 153 Tahun 2002 Tentang Baku Mutu Udara Ambien Daerah di Provinsi D.I. Yogyakarta.

Walpole, R.E., 1995, Pengantar Statistika, Jakarta: PT Gramedia Pustaka Utama.

Wardhana, W.A., 1995, Dampak Pencemaran Lingkungan, ANDI Offset, Yogyakarta. 